\title{
Deliberate self-harm in adolescent psychiatric outpatients in Singapore: prevalence and associated risk factors
}

Cheryl $\underline{L o h}^{1}$, MBBS, MMed, Yan Wen $\underline{T e O}^{1}$, M Clin Psych, Lily $\underline{\operatorname{Lim}}^{2}$, MBBS, MRCPCH

INTRODUCTION Deliberate self-harm (DSH) is frequently seen in adolescents with a range of mental health problems. The prevalence and features of DSH vary among different countries and settings. This study examines the prevalence of self-harm in a sample of adolescents seen at a psychiatric outpatient clinic in Singapore.

METHODS Information regarding self-harm, as well as its associated demographic and clinical risk factors, was extracted from the clinical records of 542 consecutive, new patients, aged 12-19 years, who presented between 2006 and 2010.

RESULTS DSH was reported in $23.6 \%$ of patients, and was positively associated with the female gender (odds ratio [OR] 4.54), mood disorders (OR 4.58), adjustment disorders (OR 3.41) and regular alcohol use (OR 4.80). However, there was no association with parental marital status, anxiety disorder, habitual smoking or family history of psychiatric illness.

CONCLUSION DSH is a significant clinical problem that may be influenced by biological and clinical factors. Adolescents presenting with DSH should be examined for mood and alcohol use disorders.

Keywords: adolescent outpatients, deliberate self-harm

\section{INTRODUCTION}

Deliberate self-harm (DSH) is frequently encountered in mental health work involving adolescents. Recently completed largescale community studies suggest varying rates of self-harm in the community, with estimates of current self-harm ranging from $1.8 \%^{(1)}$ to $17.0 \%{ }^{(2)}$ in different populations. A multicentre European study of young people found that the prevalence of DSH in women was nearly 3.5 times of that in men, ${ }^{(3)}$ whereas two Asian studies reported no gender differences in its prevalence. ${ }^{(2,4)}$ Differences were also seen in the predominant methods of self-harm. While self-cutting was predominant in Western communities, ${ }^{(1,3,5)}$ a recent Chinese survey found selfhitting to be most common among Chinese adolescents and young adults. ${ }^{(2)}$ However, it is likely that variations in the definition of self-harm, as well as in the data collection methods employed, may have contributed to some of the differences observed in the results of these studies.

Community studies have found DSH to be associated with symptoms such as depressed mood, anxiety, impulsivity, low self-esteem, eating disorder and suicidal ideation, ${ }^{(5-8)}$ as well as behaviours such as alcohol, tobacco and substance abuse. ${ }^{(2,5,8)}$ Associations with psychosocial factors such as poor school performance, poor family relationships, ${ }^{(1)}$ history of abuse, exposure to self-harm in family members and friends, ${ }^{(5)}$ recent distressing events ${ }^{(6)}$ and low economic status ${ }^{(2)}$ have also been described. It should also be noted that clinical cohorts commonly present a more severely impaired population. Adolescents with self-harming behaviour make up $14.8 \%-42 \%$ of clinic patients, ${ }^{(9,10)}$ and have been associated with diagnoses such as borderline personality disorder, post-traumatic stress disorder, dissociative disorder and depressive symptoms. ${ }^{(10,11)}$ Among adolescents diagnosed with depression, $\mathrm{DSH}$ is associated with greater severity of depression, less perceived support, younger age and more alcohol use. ${ }^{(12)}$ In a separate study, alcohol use when depressed and heavy episodic drinking were associated with suicide attempts in adolescents. ${ }^{(13)}$ Growing evidence attests to the clinical importance of $\mathrm{DSH}$. Two recent large studies on depressed adolescents found nonsuicidal self-injury to be an independent predictor of suicide attempts. ${ }^{(14,15)}$ There have been suggestions that since these episodes were regarded as non-suicidal, less suicide prevention interventions were implemented for these patients. ${ }^{(14)}$

In light of the varying, and sometimes negative, attitudes toward adolescents who present with self-harm, ${ }^{(16,17)}$ studies on self-harm in adolescents are intimately related to raising awareness of the condition and improving service provision for these patients. Given the range of findings and lack of local data, we undertook this study to investigate the prevalence

${ }^{1}$ Division of Psychological Medicine, Changi General Hospital, Singapore, ${ }^{2}$ Institute of Health Policy, Management and Evaluation, University of Toronto, Ontario, Canada

Correspondence: Dr Cheryl Loh, Consultant, Division of Psychological Medicine, Changi General Hospital, 2 Simei Street 3 , Singapore 529889. Cheryl_loh@cgh.com.sg 
of DSH, and the clinical and demographic characteristics associated with the condition, in a population of adolescent psychiatric outpatients presenting to the psychiatric service of our hospital.

\section{METHODS}

Approval for the study was obtained from the institutional review board. Data was collected from the medical records of all new patients (age range 12-19 years) seen at the psychiatry outpatient clinic of Changi General Hospital, Singapore, between 2006 and 2010. The medical records of one patient could not be traced. Patients were classified according to their birth year, and information about their gender, race and nationality was sourced from birth certificates or national identity cards. Other demographic and clinical information (e.g. employment, family history, parental marital status, living arrangements, and history of alcohol use or smoking) was found in the initial routine psychiatric interview records and from the records of allied health staff, such as psychologists and social workers, who had also interviewed the patient for the same presentation.

We observed a wide variation in the quantity of alcohol and cigarettes consumed by the patients. However, this information was not quantified, except by denoting regular users of cigarettes and alcohol as those who engage in the habit more than once a week. A vast majority of patients in our cohort exceeded this threshold. The main diagnosis recorded by the attending psychiatrist after the first interview was used. In the present study, depressive disorders included major depression, dysthymia and minor depressive illness, and anxiety disorders included generalised anxiety disorder, panic disorder, obsessive-compulsive disorder, post-traumatic stress disorder and phobias. DSH was defined as direct self-injury or poisoning, regardless of motivation and excluding culturally sanctioned procedures. It was recorded to be present in a patient whenever an act meeting the aforementioned description was encountered. Patients with and without DSH were compared for variables thought to be clinically or epidemiologically significant such as gender, parental marital status, family history of psychiatric disorder, depressive disorder, anxiety disorder and adjustment disorder.

In the univariate analysis of relevant factors associated with DSH, all variables were compared using chi-square test. A value of $p<0.05$ was considered statistically significant. Candidate risk factors were screened during univariate logistic regression analysis and variables with $p$-values $<0.2$ were further analysed via multivariate regression. Variables with $p>0.05$ on multivariate regression were excluded. Risk factors identified on multivariate regression analysis were compared for fit using the likelihood ratio test, based on chi-square test. The goodness of fit of the final candidate models were tested with the Le Cessie-van Houwelingen test. ${ }^{(18)}$ All data manipulation was performed using R 2.13.1
Table I. Selected characteristics of adolescent psychiatric outpatients $(n=542)$.

\begin{tabular}{|c|c|}
\hline Characteristic & No. (\%) \\
\hline \multicolumn{2}{|l|}{ Race } \\
\hline Chinese & $391(72.1)$ \\
\hline Malay & $91(16.8)$ \\
\hline Indian & $31(5.7)$ \\
\hline Eurasian & $3(0.6)$ \\
\hline Other & $26(4.8)$ \\
\hline \multicolumn{2}{|l|}{ Gender } \\
\hline Female & $230(42.4)$ \\
\hline Male & $312(57.6)$ \\
\hline \multicolumn{2}{|l|}{ Employment status } \\
\hline Full time student & $373(68.8)$ \\
\hline National service & $87(16.1)$ \\
\hline Employed & $46(8.5)$ \\
\hline Not working or in school & $35(6.5)$ \\
\hline Other* & $1(0.2)$ \\
\hline \multicolumn{2}{|l|}{ Parental status } \\
\hline Married & $440(81.2)$ \\
\hline Unmarried/divorced/separated & $77(14.2)$ \\
\hline Deceased & $21(3.9)$ \\
\hline Patient adopted & $3(0.6)$ \\
\hline Other ${ }^{+}$ & $1(0.2)$ \\
\hline \multicolumn{2}{|l|}{ Living arrangement } \\
\hline With both parents & $431(79.5)$ \\
\hline With single parent & $63(11.6)$ \\
\hline In blended families & $19(3.5)$ \\
\hline With other relatives & $16(3.0)$ \\
\hline Other & $13(2.4)$ \\
\hline \multicolumn{2}{|l|}{ Main diagnosis } \\
\hline Depressive disorder & $130(24.0)$ \\
\hline Anxiety disorder & $123(22.7)$ \\
\hline Adjustment disorder & $123(22.7)$ \\
\hline Eating disorder & $22(4.1)$ \\
\hline Psychotic disorder & $21(3.9)$ \\
\hline Learning disorder & $13(2.4)$ \\
\hline Substance use disorder & $3(0.6)$ \\
\hline No mental illness & $42(7.7)$ \\
\hline Other & $65(12.0)$ \\
\hline \multicolumn{2}{|l|}{ Current or past history } \\
\hline Smoking & $122(22.5)$ \\
\hline Alcohol use & $109(20.1)$ \\
\hline \multicolumn{2}{|l|}{ Family history of psychiatric illness } \\
\hline First degree relative & $79(14.6)$ \\
\hline Other relatives & $69(12.7)$ \\
\hline
\end{tabular}

*Irregular employment or undergoing part-time education. ${ }^{\dagger}$ No known parents.

for Windows (The R Foundation for Statistical Computing; Vienna, Austria/www.r-project.org).

\section{RESULTS}

A total of 542 adolescents (mean age $17.4 \pm 1.7$ years) were seen during the study period. Table I presents the demographic and clinical characteristics of the patients seen in our study. A history of DSH was seen among 128 (23.6\%) patients in this group. The unspecified diagnoses (i.e. 'Other') in Table I refer to a wide range of diagnoses including acute situational reactions, behavioural problems, problems related to gender identity disorders, psychiatric symptoms related to organic problems, and autism spectrum disorders; many of these diagnoses had low numbers. Table II compares the risk factors of patients with and without DSH. Among patients with DSH, 68.75\% 
Table II. Risk factors of adolescent psychiatric outpatients with and without deliberate self-harm (DSH).

\begin{tabular}{lcrr}
\hline Factor & \multicolumn{2}{c}{ No. of patients (\%) } & p-value \\
\cline { 2 - 3 } & With DSH (n = 128) & Without DSH (n = 414) & $<0.0001$ \\
\hline Female gender & $88(68.75)$ & $142(34.30)$ & 0.0247 \\
Married parents & $95(74.22)$ & $346(83.57)$ & $<0.0001$ \\
Depressive disorder & $52(40.63)$ & $78(18.84)$ & $<0.0001$ \\
Anxiety disorder & $8(6.25)$ & $115(27.78)$ & 0.002 \\
Adjustment disorder & $45(35.16)$ & $78(18.84)$ & 0.592 \\
Psychotic disorder & $3(2.34)$ & $18(4.35)$ & 0.532 \\
Substance use disorder & $1(0.78)$ & $2(0.48)$ & 0.5887 \\
Positive family history of psychiatric illness & $32(25.00)$ & $116(28.02)$ & 0.0626 \\
Smoking & $37(28.91)$ & $85(20.53)$ & $<7(16.18)$ \\
Alcohol use & $42(32.81)$ & & $<.0001$ \\
\hline
\end{tabular}

Table III. Logistic regression analysis of risk factors associated with deliberate self-harm in adolescent psychiatric outpatients.

\begin{tabular}{|c|c|c|c|c|}
\hline \multirow[t]{2}{*}{ Factor } & \multicolumn{2}{|c|}{ Univariate analysis } & \multicolumn{2}{|c|}{ Multivariate analysis } \\
\hline & OR $(95 \% \mathrm{Cl})$ & p-value & OR $(95 \% \mathrm{CI})$ & p-value \\
\hline Gender & $4.21(2.77-6.50)$ & $<0.0001$ & $4.53(2.85-7.37)$ & $<0.0001$ \\
\hline Parental marital status & $1.77(1.09-2.82)$ & 0.019 & - & - \\
\hline Depressive disorder & $2.96(1.91-4.53)$ & $<0.0001$ & $4.58(2.67-7.96)$ & $<0.0001$ \\
\hline Anxiety disorder & $0.17(0.08-0.34)$ & $<0.0001$ & - & - \\
\hline Adjustment disorder & $2.34(1.50-3.62)$ & 0.0002 & $3.41(2.77-5.80)$ & $<0.0001$ \\
\hline Psychotic disorder & $0.57(0.17-1.97)$ & 0.343 & - & - \\
\hline Substance use disorder & $4.21(2.77-6.50)$ & $<0.0001$ & - & - \\
\hline $\begin{array}{l}\text { Positive family history } \\
\text { of psychiatric illness }\end{array}$ & $1.77(1.09-2.82)$ & 0.019 & - & - \\
\hline Smoking & $0.17(0.08-0.34)$ & $<0.0001$ & - & - \\
\hline Alcohol use & $2.96(1.91-4.53)$ & $<0.0001$ & $4.80(2.02-8.44)$ & $<0.0001$ \\
\hline
\end{tabular}

$\mathrm{Cl}$ : confidence interval; OR: odds ratio

of patients were female, $28.91 \%$ smoked regularly and $32.81 \%$ consumed alcohol regularly. Many patients with DSH had depressive and adjustment disorders, although comparatively few had anxiety disorders. Most patients with DSH came from families with parents who were still married $(74.22 \%)$, and one in four patients had a positive family history of psychiatric illness.

On logistic regression analysis, four factors were found to be independently associated with DSH - female gender, mood disorders, adjustment disorders and regular alcohol use. These factors were more frequent among patients with DSH compared to patients without DSH (Table III). There was no significant difference between patients with and without DSH with respect to factors such as parental marital status, positive family history of mental illness and regular smoking.

\section{DISCUSSION}

In our study of 542 adolescent patients, we found that $128(23.6 \%)$ had a history of DSH. Our findings were moderate compared to the prevalence of DSH previously reported in other clinical populations. ${ }^{(9,10)}$ A comparison of our findings with the national prevalence rates for smoking $(9 \%-19 \%)^{(19,20)}$ and regular alcohol use $(21.7 \%)^{(21)}$ indicated that adolescent psychiatric outpatients exhibited higher rates of both behaviours. While the association between alcohol use and DSH has been previously reported, ${ }^{(2,5)}$ others have refuted this association. ${ }^{(7)}$ Alcohol use is thought to increase the risk of DSH by lowering inhibitions and increasing impulsivity. However, in cultures where alcohol is more widely available, alcohol use may be a means of emotional regulation, thus possibly replacing other more overt forms of self-harm. Unlike alcohol, the reasons for the association between smoking and DSH are less clear. It is possible that smoking in Singapore is associated with antisocial behaviour, thereby implying characteristics such as impulsivity, which may be seen as a factor for the increase of self-harm tendencies.

Other associations (between DSH and the risk factors) found in the present study mirror the findings of previously published studies, ${ }^{(5-8)}$ which are mostly from Western countries. Clinically diagnosed depression is a strong risk factor for DSH. In the present study, DSH was strongly associated with depression, a condition that commonly manifests with loss of pleasure, lack of energy, poor concentration, and thoughts of dying and suicide. The aforementioned finding concurs with prior research on the reasons behind adolescent DSH, which suggested that the condition is often an ambivalent 
combination of suicidal thoughts and gaining relief from negative feelings. ${ }^{(22-24)}$ However, we did not find any association between adolescent DSH and anxiety disorder. This may be due to the small number of patients with anxiety disorder in our population.

Although adjustment disorders are a frequent clinical diagnosis in adolescent clinical populations, they have not been investigated extensively. ${ }^{(25,26)}$ One contributing factor to this lack of research may be the use of standardised diagnostic interviews in clinical trials that either exclude adjustment disorders entirely or allow it only in the absence of any other disorder. While the long-term prognosis and diagnostic stability of adjustment disorders are not fully known, there are suggestions that it is not as mild or temporary in adolescents as was commonly thought. ${ }^{(27)}$ For instance, a longitudinal study by Lewinsohn et al found that adolescents with adjustment disorders experienced similar rates of major depressive disorders and nonaffective disorders in young adulthood as adolescents with major depressive disorders. ${ }^{(27)}$ It is not known whether the diagnosis of adjustment disorder in the study by Lewinsohn et $\mathrm{al}^{(27)}$ was made because of a coincident stressor or an overlap with major depressive disorder. Studies by Pelkonen et $\mathrm{al}^{(28)}$ and Portzky et al ${ }^{(29)}$ have, however, specifically investigated adjustment disorders in adolescents. Pelkonen et $\mathrm{al}^{(28)}$ found that suicidal tendencies were present in $25 \%$ of adolescent outpatients diagnosed with adjustment disorder. Similarly, a psychological autopsy by Portzky et al ${ }^{(29)}$ indicated an association between adjustment disorders and completed adolescent suicide.

There were several limitations in our study. As data on the economic status of our patients was unavailable, we could not ascertain its role in DSH. The number of patients with substance use disorder in our study was small, and this may have been a confounding factor where the association between substance use and adolescent self-harm is concerned. We also noted that other than as a main diagnosis, there was a general lack of notes regarding illicit substance use among patients. This may either reflect the low prevalence of such problems in our clinical population or hint at a general reluctance in enquiring about such behaviour. As no formal diagnostic interview was used in our study, the broadly defined diagnostic groups presented in this report should be interpreted with care. Our study sample is a clinical sample that does not represent the general population; the prevalence observed in our group of patients is likely to be similar to that of a more severely distressed group.

Several novel therapies for DSH in adolescents have been evaluated. Developmental group psychotherapy ${ }^{(30)}$ uses group processes to teach management of common conflict areas. A pilot study by Wood et al was able to show a decrease in the likelihood of self-harm through the use of group therapies, ${ }^{(30)}$ although such findings were not replicated in later studies. ${ }^{(31,32)}$ Other approaches for the treatment of DSH include dialectical behaviour therapy, multisystemic therapy, mentalisation-based therapy and specific cognitive behavioural therapy (CBT). Although these therapies have yet to be specifically evaluated in self-harm populations and randomised controlled trials, there has been some evidence regarding their use in the treatment of self-harm and suicidal tendencies in patients with depression. For example, the Treatment of Adolescent Depression Study suggested that the implementation of $\mathrm{CBT}$, in addition to the administration of fluoxetine, reduces suicidal tendencies in depressed adolescents. ${ }^{(33)}$ However, this was not reported in other depression treatment trials. Other studies encountered problems and confounding differences like a lack of power (e.g. in the Youth Partners in Care trial ${ }^{(34)}$ ) and a greater severity of depression (e.g. in the Adolescent Depression Antidepressant and Psychotherapy Trial ${ }^{(35)}$ and Treatment of SSRI-Resistant Depression in Adolescents study ${ }^{(36)}$ ). There remains much to be investigated in the area of adolescent DSH.

A community-based Singapore study with longitudinal follow-up would greatly increase our understanding of this behavioural syndrome, especially in the identification of those at increased risk of complete suicide and adult mental illnesses. Going forward, the next step would be the evaluation of a treatment package, which should be feasible and accessible in the local context. Our present study suggests that interventions that address common comorbidities such as problematic alcohol use would be useful. The role of the family in therapy may also be more prominent than currently perceived, given that most patients with DSH in our study came from intact families. Clinicians should bear in mind that the indiscriminate importation of interventions from other countries - where there may be relevant differences in the views of therapy or family roles - may result in these interventions functioning differently in the Singapore context. Many of the aforementioned therapies also involve specifically trained therapists and intensive patient contact, thus highlighting a need for evidence that these therapies would be practical and efficacious in Singapore.

In conclusion, this study gives an estimate of the extent of DSH among adolescents seen in Singapore outpatient clinics, and indicates the clinical and demographic risk factors associated with this condition. As suggested by the present study, DSH may very much be influenced by biological and clinical factors. We therefore propose that this consideration should inform clinicians' attitudes and the clinical care of adolescents presenting with DSH. Our findings also indicate that we should expect a high rate of depressive and adjustment disorders among local adolescent psychiatric outpatients with DSH, as well as look out for associated alcohol use behaviours. Adjustment disorder, which is routinely diagnosed in adolescents with $\mathrm{DSH}$, warrants more investigation and longitudinal follow-up. Further research may focus on intervention outcomes in view of the various risk factors identified. 


\section{REFERENCES}

1. Laukkanen E, Rissanen ML, Honkalampi K, et al. The prevalence of self-cutting and other self-harm among 13- to 18-year old Finnish adolescents. Soc Psychiatry Psychiatr Epidemiol 2009; 44:23-8.

2. Wan $\mathrm{YH}, \mathrm{Hu} \mathrm{CL}$, Hao JH, Sun $\mathrm{Y}$, Tao FB. Deliberate self-harm behaviours in Chinese adolescents and young adults. Eur Child Adolesc Psychiatry 2011; 20:517-25.

3. Madge N, Hewitt A, Hawton K, et al. Deliberate self-harm within an international community sample of young people: comparative findings from the Child and Adolescent Self-harm in Europe (CASE) study. J Child Psychol Psychiatry 2008; 49:667-77.

4. Shin YM, Chung YK, Lee YM, Oh EY, Cho SM. Childhood predictors of deliberate self-harm behaviour and suicide ideation in Korean adolescents: a prospective population-based follow-up study. J Korean Med Sci 2009; 24:215-22.

5. Hawton K, Rodham K, Evans E, Weatherall R. Deliberate self harm in adolescents: self report survey in schools in England. BMJ 2002; 325:1207-11.

6. De Leo D, Heller TS. Who are the kids who self-harm? An Australian self-report school survey. Med J Aust 2004; 181:140-4.

7. Brunner R, Parzer P, Haffner J, et al. Prevalence and Psychological correlates of occasional and repetitive deliberate self-harm in adolescents. Arch Pediatr Adolesc Med 2007; 161:641-9.

8. Moran P, Coffey C, Romaniuk $\mathrm{H}$, et al. The natural history of self-harm from adolescence to young adulthood: a population-based cohort study. Lancet 2012; 379:236-43.

9. Pelkonen M, Marttunen M, Pulkkinen E, Laippala P, Aro H. Characteristics of out-patient adolescents with suicidal tendencies. Acta Psychiatr Scand 1997; 95:100-7.

10. Csorba J, Dinya E, Plener P, Nagy E, Páli E. Clinical diagnoses, characteristics of risk behaviour, differences between suicidal and non-suicidal subgroups of Hungarian adolescent outpatients practising self-injury. Eur Child Adolesc Psychiatry 2009; 18:309-20.

11. Hintikka J, Tolmunen T, Rissanen ML, et al. Mental disorders in self-cutting adolescents. J Adolesc Health 2009; 44:464-7.

12. Tuisku V, Pelkonen M, Kiviruusu O, et al. Factors associated with deliberate self-harm behaviour among depressed adolescent outpatients. J Adolesc 2009; 32:1125-36.

13. Schilling EA, Aseltine RH Jr, Glanovsky JL, James A, Jacobs D. Adolescent alcohol use, suicide ideation, and suicide attempts. J Adolesc Health 2009; 44:335-41.

14. Asarnow JR, Porta G, Spirito A, et al. Suicide attempts and nonsuicidal self-injury in the treatment of resistant depression in adolescents: findings from the TORDIA study. J Am Acad Child Adolesc Psychiatry 2011; 50:772-81.

15. Wilkinson P, Kelvin R, Roberts C, Dubicka B, Goodyer I. Clinical and psychosocial predictors of suicide attempts and nonsuicidal self-injury in the Adolescent Depression Antidepressants and Psychotherapy Trial (ADAPT). Am J Psychiatry 2011; 168:495-501.

16. Anderson M, Standen P, Noon J. Nurses' and doctors' perceptions of young people who engage in suicidal behaviour: a contemporary grounded theory analysis. Int J Nurs Stud 2003; 40:587-97.

17. Platt S, Salter D. A comparative investigation of health workers' attitudes towards parasuicide. Soc Psychiatry 1987; 22:202-8.

18. Le Cessie S, van Houwelingen JC. A goodness-of-fit test for binary regression models, based on smoothing methods. Biometrics 1991; 47:1267-82.

19. Students Health Survey. Singapore: Health Promotion Board, 2006.

20. Subramaniam M, Cheok C, Lee IM, et al. Nicotine dependence and psychiatric disorders among young males in Singapore. Nicotine Tob Res 2009; 11:1107-13.

21. Lew K, Barlow PJ. Dietary practices of adolescents in Singapore and Malaysia. Singapore Med J 2005; 46:282-8.

22. Scoliers G, Portzky G, Madge N, et al. Reasons for adolescent deliberate self-harm: a cry of pain and/or a cry for help? Soc Psychiatry Psychiatr Epidemiol 2009; 44:601-7.

23. Klonsky ED. The functions of deliberate self-harm: a review of the evidence. Clin Psychol Rev 2007; 27:226-39.

24. Boergers J, Spirito A, Donaldson D. Reasons for adolescent suicide attempts: associations with psychological functioning. J Am Acad Child Adolesc Psychiatry 1998; 37:1287-93.

25. Lee NBC, Fung D, Teo J, Chan YH, Cai YM. Five-year review of adolescent mental health usage in Singapore. Ann Acad Med Singapore 2003; 32:7-11.

26. Pelkonen M, Marttunen M, Henriksson M, Lönnqvist J. Adolescent adjustment disorder: precipitant stressors and distress symptoms of 89 outpatients. Eur Psychiatry 2007; 22:288-95.

27. Lewinsohn PM, Rohde P, Klein DN, Seeley JR. Natural course of adolescent major depressive disorder: I. Continuity into young adulthood. J Am Acad Child Adolesc Psychiatry 1999; 38:56-63.

28. Pelkonen M, Marttunen M, Henriksson M, Lönnqvist J. Suicidality in adjustment Disorder -clinical characteristics of adolescent outpatients. Eur Child Adolesc Psychiatry 2005; 14:174-80.

29. Portzky G, Audenaert K, van Heeringen K. Suicide among adolescents. A psychological autopsy study of psychiatric, psychosocial and personalityrelated factors. Soc Psychiatry Psychiatr Epidemiol 2005; 40:922-30.

30. Wood A, Trainor G, Rothwell J, Moore A, Harrington R. Randomized trial of group therapy for repeated deliberate self-harm in adolescents. J Am Acad Child Adolesc Psychiatry 2001; 40:1246-53.

31. Hazell PL, Martin G, McGill K, et al. Group therapy for repeated deliberate self-harm in adolescents: failure of replication of a randomized trial. J Am Acad Child Adolesc Psychiatry 2009; 48:662-70.

32. Green JM, Wood AJ, Kerfoot MJ, et al. Group therapy for adolescents with repeated self harm: randomised controlled trial with economic evaluation. BMJ 2011; 342:d682.

33. March J, Silva S, Petrycki S, et al. Fluoxetine, cognitive-behavioral therapy, and their combination for adolescents with depression: Treatment for Adolescents With Depression Study (TADS) randomized controlled trial. JAMA 2004; 292:807-20.

34. Asarnow JR, Jaycox LH, Tang L, et al. Long-term benefits of short-term quality improvement interventions for depressed youths in primary care. Am J Psychiatry 2009; 166:1002-10.

35. Goodyer I, Dubicka B, Wilkinson P, et al. Selective serotonin reuptake inhibitors (SSRIs) and routine specialist care with and without cognitive behaviour therapy in adolescents with major depression: randomised controlled trial. BMJ 2007; 335:142.

36. Brent D, Emslie G, Clarke G, et al. Switching to another SSRI or to venlafaxine with or without cognitive behavioral therapy for adolescents with SSRI-resistant depression: the TORDIA randomized controlled trial. JAMA 2008; 299:901-13. 